\title{
Demonstration of Epstein-Barr virus in primary brain lymphoma by in situ DNA hybridisation in paraffin wax embedded tissue
}

\author{
J K Murphy, L S Young, I S Bevan, F A Lewis, D Dockey, J W Ironside, C J O’Brien, \\ M Wells
}

\begin{abstract}
Tumour tissue from 29 patients with primary brain lymphoma was reviewed to determine if there was an aetiological association between Epstein-Barr virus and polyclonal and monoclonal lymphoproliferations. The morphology and immunophenotype in 24 patients for whom paraffin wax embedded tissue was available were studied. A high grade pleomorphic tumour morphology with plasmacytoid features was seen in 13 tumours. Because of the large number of pleomorphic lymphomas, all tumours were examined for the presence of the Epstein-Barr virus genome using in situ DNA hybridisation. A panel of three biotinylated probes to different sequences in the Epstein-Barr virus genome was used. Positive hybridisation with one or more probes was shown in tumours from 11 patients. The remaining tumours gave no hybridisation signal. There was no correlation between positive hybridisation and morphological subtype or clinical outcome.
\end{abstract}

Primary brain lymphoma represents only $1 \%$ of all primary intracranial neoplasms and a smaller percentage of all cases of non-Hodgkin's lymphoma, both nodal and extra-nodal in site. ${ }^{12}$ Many studies have shown a striking increase in incidence of this tumour, both in immunosuppressed and non-immunosuppressed populations. ${ }^{13}$ Regardless of treatment modality or clinical state, these tumours are associated with a very poor prognosis.

The Epstein-Barr virus, a B cell lymphotrophic herpes virus, has been associated with and proposed as an aetiological agent in both benign and malignant lymphoproliferations. ${ }^{124-6}$ Epstein-Barr virus is strongly associated and implicated in the aetiology of both Burkitt's lymphoma ${ }^{78}$ and lymphomas arising after transplantation..$^{912}$ In the endemic variety of Burkitt's lymphoma a chromosomal translocation involving the $c-m y c$ oncogene occurs in association with the virus in all tumours..$^{813}$ Systemic lymphomas in hereditary ataxiatelangiectasia have been shown to contain the Epstein-Barr virus genome. ${ }^{1415}$ Patients with AIDS are also predisposed to the development of lymphoma. ${ }^{17}$ In the X-linked lymphoproliferative syndrome, described by Purtilo in the Duncan kindred, there is an ineffective immune response to Epstein-Barr virus. ${ }^{151819}$ Infection in the affected person results in a spectrum of B lymphocyte disorders including lymphoma. Similarly, infection in the cottontop Tamarin, the animal model for the Duncan syndrome, results in oligoclonal B cell lymphoproliferations. ${ }^{20}$ Experimental transplantation of B lymphocytes infected with EpsteinBarr virus in nude mice has resulted in both polyclonal and monoclonal lymphoproliferations. ${ }^{21}$ Similar results have been reported in studies of infected B lymphocytes in vitro. ${ }^{6}$

Southern blot hybridisation studies have shown the presence of the Epstein-Barr virus genome in at least five cases of primary central nervous system lymphoma. ${ }^{416}$ Furthermore, serological studies have shown evidence of persistent or reactivated Epstein-Barr virus infection in cases of primary central nervous system lymphoma. ${ }^{1}$ As a corollary, an EpsteinBarr virus-like herpes virus has been associated with enzootic outbreaks of systemic lymphoma in baboons. ${ }^{22}$

The Epstein-Barr virus genome is a linear double stranded DNA molecule of 172 kilobases. ${ }^{23}$ Restriction endonuclease maps have been derived and the entire genome cloned and sequenced. The genome is composed of "unique" and "repeat" DNA elements. Restriction endonucleases divide the genome into shorter variable sequences. In this study we analysed three distinct regions of the viral genome. The $B a m W$ sequence is 3.3 kilobases in length, is the product of the restriction enzyme BamH1, and is a "repeat" sequence. Epstein-Barr nuclear antigen leader protein ${ }^{24}$ or EBNA5 is encoded by highly spliced exons from the BamH1WY region of the genome. Finally, the Dhet sequence is 12.4 kilobases and incorporates the LT3 gene and nearby unique regions.

Lymphomas occurring in the context of Epstein-Barr virus infection are described as high grade pleomorphic tumours. ${ }^{12}$ We recently reviewed a series of 29 primary brain lymphomas collected from three neurosurgical units in the Yorkshire Regional Health Authority over 18 years. ${ }^{3}$ The morphology and immunophenotype were studied in 24 cases for which paraffin wax embedded material was available. A high grade pleomorphic tumour morphology was observed in 13 cases. With such a predominant tumour type in our series we investigated all the tumours for the presence 
of the Epstein-Barr virus genome by in situ DNA hybridisation, using a panel of biotinylated probes to different regions of the viral genome and a polyakaline phosphate complex detection system.

\section{Methods}

Details of the tumours studied have been reported elsewhere. ${ }^{3}$ Briefly, tumour tissue was available from 16 males and 13 females (age range $6-80$ years) as 23 surgical specimens and six necropsy specimens. There was no overt evidence of immunosuppression in any patient. Twenty four tumours were supratentorial in site and nine had a multifocal distribution in the brain. Formalin fixed, paraffin wax embedded tissue was available for study from 24 patients. The tumours were $B$ cell nonHodgkin's lymphomas; most were high grade showing a prominent pleomorphic morphology (figure 1) while three were of low grade lymphoplasmacytoid type.

In situ hybridisation studies were performed on the 24 cases where paraffin wax embedded tissue was available. Probes to the $B a m W$, leader protein, and Dhet sequences of the Epstein-Barr virus genome were biotinylated using biotin-11-dUTP by nick translation using standard protocols. Hybridisation was visualised using the streptavidin-biotinpolyalkaline phosphatase technique.

The details of the in situ hybridisation technique have previously been published. ${ }^{25}$ In summary, the material was first pretreated to ensure maximal penetration of the probes: sections $5 \mu \mathrm{m}$ thick on three aminopropyltriethoxysilane coated (Sigma Chemical Company, Poole, Dorset) single well slides (Hendley Ltd, Essex) were dewaxed and rehydrated. The sections were treated with the detergent Triton X-100 to permeabilise membranes and then digested with the protease, proteinase K (Gibco-BRL, Paisley, Scotland). The sections were then treated with acetic acid to destroy endogenous alkaline phosphatase,

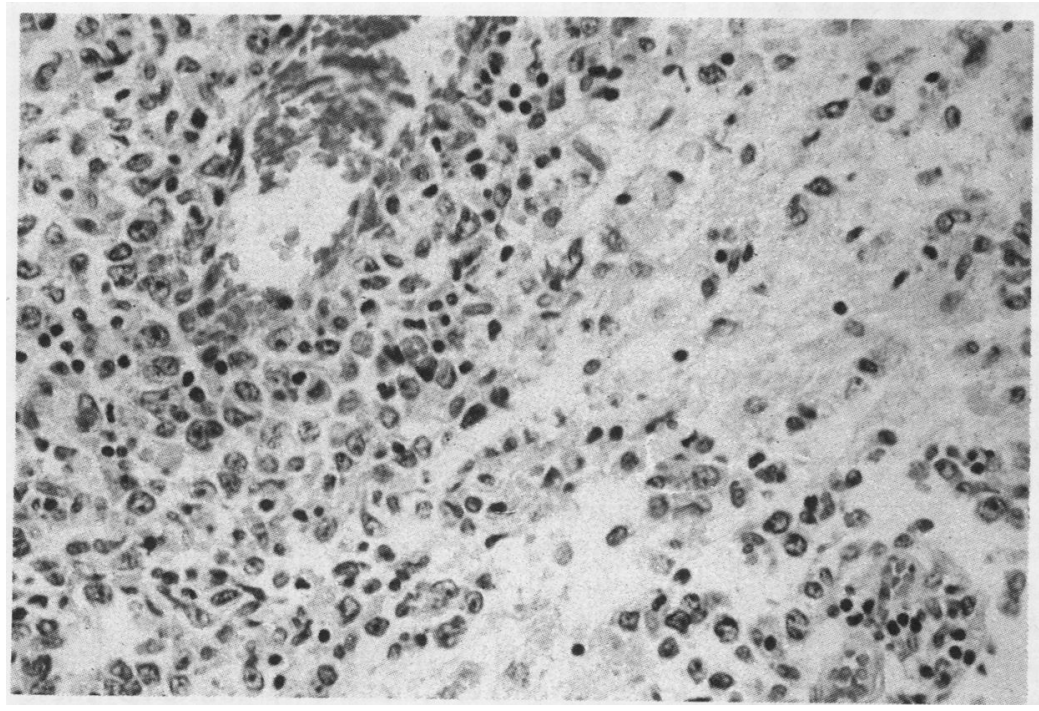

Figure 1 Primary brain lymphoma showing a high grade pleomorphic morphology and a predominantly perivascular distribution (Haematoxylin and eosin). refixed in paraformaldehyde, and dehydrated. Parallel sections were also treated separately with RNAse $A$ and DNAse 1 to identify the nucleic acid visualised after hybridisation.

Biotinylated probes to $B a m W$, leader protein, and Dhet sequences in a hybridisation buffer containing $2 \times \mathrm{SSC}, 5 \%$ dextran sulphate, $0 \cdot 2 \%$ dried milk powder and $50 \%$ formamide were added to all the sections at a concentration of $200 \mathrm{ng} / \mathrm{ml}$. Biotinylated total human DNA was used as a positive control while the hybridisation buffer alone and biotinylated plasmid were used as negative controls. The cellular and probe DNA were denatured by heating the slides to $90^{\circ} \mathrm{C}$ for 10 minutes and hybridisation was carried out at $42^{\circ} \mathrm{C}$ overnight. $(1 \times \mathrm{SSC}=0 \cdot 15 \mathrm{M}$ sodium chloride, $0.015 \mathrm{M}$ sodium citrate).

After stringent washes to remove excess probe and mismatched hybrids the hybridisation signal was detected by the addition of the protein tetramer streptavidin (Dako) which has a high affinity for biotin. Biotinylated alkaline phosphatase (Dako) was then added to react with the remaining biotin binding sites on the streptavidin. The alkaline phosphatase was visualised using the substrates nitrobluetetrazolium (NTB) (Gibco-BRL) and 5-bromo-4-chloro-3-indolylphosphate (BCIP) (Gibco-BRL) to produce a purple precipitate at the site of hybridisation. The sections were counterstained using $2 \%$ methyl green.

The probes have been validated and have shown hybridisation in a lymph node from a case of infectious mononucleosis and in cells of the Raji cell line. Furthermore, a lymph node from a confirmed case of infectious mononucleosis was used in this study in parallel, as a positive control tissue.

\section{Results}

The results of in situ hybridisation for EpsteinBarr virus DNA in primary brain lymphomas are summarised in the table. A particulate or multiple dot pattern of hybridisation signal was seen in 11 tumours with the $B a m W$ probe (figure 2), eight tumours with the leader protein probe and in seven tumours with the Dhet probe. Seven tumours were consistently positive with all three probes, while one tumour showed hybridisation with only two probes and three tumours hybridised only with the $B a m W$ probe. A stronger signal was visualised using the $B a m W$ probe when compared with that of the other probes. This is due to the presence of multiple repeats of the former sequence in the viral genome compared with

Results of in situ hybridisation on primary brain lymphomas

\begin{tabular}{lll}
\hline Classification (Kiel criteria) & $\begin{array}{l}\text { No of } \\
\text { surgical cases }\end{array}$ & $\begin{array}{l}\text { No of } \\
\text { necropsy cases }\end{array}$ \\
\hline High grade: & & \\
Pleomorphic & $4 / 9$ & $1 / 4$ \\
Lymphoblastic & $1 / 3$ & None \\
$\quad$ Centroblastic & $2 / 2$ & $1 / 1$ \\
Immunoblastic & None & $2 / 2$ \\
Low grade: & & None \\
\hline
\end{tabular}




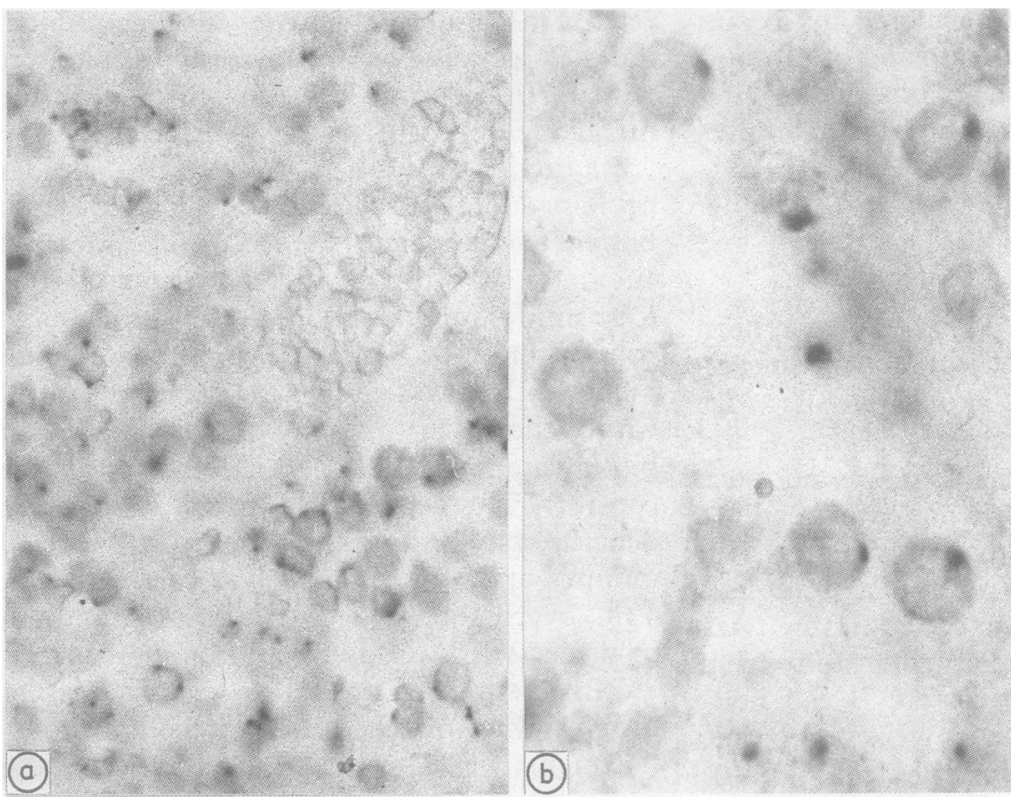

Figure 2 In situ hybridisation for the BamW repeat sequence of the Epstein-Barr virus genome in primary brain lymphoma. (a) Hybridisation signal seen in tumour cell nuclei only; endothelial cells and glial cells do not contain the sequence. (b) Individual tumour cell nuclei shows a fine multiple dot pattern of hybridisation for the BamW repeat sequence.

Figure 3 In contrast, DNA hybridisation for total human DNA gives nuclear labelling in all cells, including tumour, endothelial, and glial cells. the leader protein and Dhet sequences which are single sequences. Tumour cells had a positive hybridisation signal while surrounding normal and reactive brain cells and endothelial cells were negative. In all tumours the nucleic acid hybridised was confirmed to be DNA using the enzymes RNAse $A$ and DNAse 1. Pretreatment with DNAse abolished the signal while the use of RNAse did not affect the result. A diffuse nuclear hybridisation signal was visualised using the probe to total human DNA in tumour cells, surrounding brain cells, and in endothelial cells (figure 3).

A review of the lymphomas in conjunction with the hybridisation results showed that a

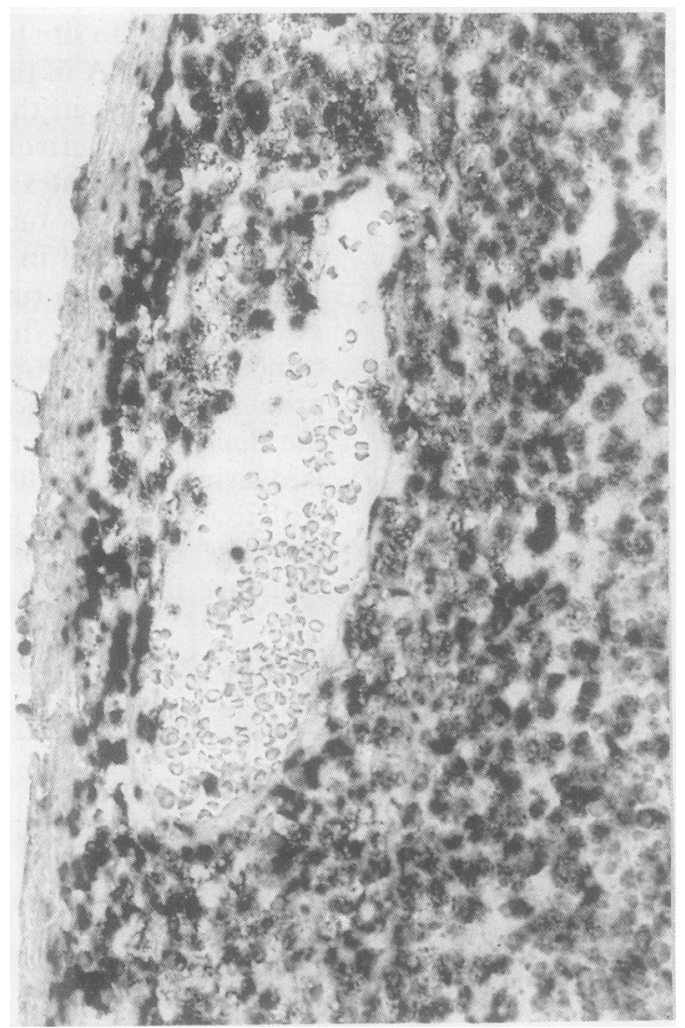

spectrum of morphological types was observed in those tumours where the Epstein-Barr virus genome was visualised. Although three low grade tumours were included in the series, only high grade tumours showed hybridisation with the probes. Light chain monoclonality, which was conclusively shown in 11 of the tumours, was present in 10 of the 11 tumours hybridising with the probes to Epstein-Barr virus sequences. No association was found between the age and sex of the patients, site of the tumour or clinical outcome, and detection of viral DNA sequences.

\section{Discussion}

The classic picture of infection with EpsteinBarr virus is infectious mononucleosis. ${ }^{5}$ In many patients infection may be asymptomatic, and by adolescence or early adulthood most people are seropositive for antibodies to various viral antigens. After primary infection the virus persists in a latent state. Both oropharyngeal epithelial cell infection and lymphocyte infection persists for years to life, with a continuous release of virus from the former but with little or no virus replication in lymphocytes. ${ }^{23}$ The latently infected lymphocytes are suppressed or killed by immunocompetent $T$ and natural killer lymphocytes. ${ }^{26} 27$

In experimental and clinical situations the uncontrolled proliferation of lymphocytes with Epstein-Barr virus has resulted in a spectrum of lymphoproliferations, including monoclonal lymphomas. Most primary brain lymphomas are high grade $B$ cell tumours. ${ }^{1-3}$ They are characteristically associated with an overwhelmingly poor prognosis, in contrast to lymphomas at other sites. The normal brain is devoid of lymphoid tissue ${ }^{2}$ and is regarded as an immunologically privileged site, a factor attributed to the blood brain barrier. A loss of repressor control, by virtue of immunosuppression or the brain's privileged state, would contribute to lymphoproliferation and development of lymphoma. It has been suggested, therefore, that Epstein-Barr virus is an aetiological agent in primary brain lymphoma. $^{1416}$

A reactive $\mathrm{T}$ lymphocyte population, possibly representing a host response to the tumour, is a commonly observed feature of both systemic and brain lymphomas. ${ }^{1-3}$ In primary brain lymphoma the $\mathrm{T}$ lymphocyte infiltrate may be specifically directed against virally infected B lymphocytes.

We have shown the presence of Epstein-Barr virus DNA in 11 primary brain lymphomas. Epstein-Barr virus DNA usually persists in cells as covalently closed circular full length episomes, but can persist solely as a complete genome integrated into cell DNA, or as both integrated and episomal DNA. ${ }^{23}$ The inability to show the presence of the viral genome in 13 tumours of our series may have been due to poor tissue fixation and preservation. In an earlier study full immunophenotypic characterisation of these tumours was limited by these factors. ${ }^{3}$ The in situ DNA hybridisation technique may not detect very low viral genome 
copy numbers, thereby limiting the sensitivity of the technique. The polymerase chain reaction can be used to amplify the number of viral copies present in a tissue. ${ }^{28}$ Preliminary studies with the polymerase chain reaction to detect $B a m W$ and Dhet sequences in DNA extracted from the paraffin wax blocks have supported our results with the in situ hybridisation technique (unpublished observations).

Immunofluorescence studies with EpsteinBarr virus immune human sera have indicated a group of at least seven virally encoded proteins, the Epstein-Barr virus nuclear antigen (EBNA), and the latent membrane protein (LMP). ${ }^{23}$ These so-called latent gene products - are constitutively expressed in all virally transformed B lymphocyte cell lines. ${ }^{23} \mathrm{~B}$ cell growth transformation in vitro seems to depend on the cooperative action of all these latent gene products. ${ }^{23}$ Two of these proteins, EBNA2 and LMP, in particular, are associated with phenotypic changes related to transformation through specific activation of cellular genes. ${ }^{29}$ The $B$ cell activation marker CD23 and the adhesion molecules LFA3 and ICAM1 are upregulated by $\mathrm{EBNA}_{2}$ and LMP in vitro. ${ }^{29} 30$ In vitro studies and studies in experimental tumours in Tamarins ${ }^{31}$ and in B lymphocyte proliferations in immunodeficient patients (unpublished observations) have shown variable but consistent expression of these effector molecules. Integration of the viral genome, which occurs in Burkitt's lymphoma and the Namalwa cell line, does not seem to be the main factor in lymphocyte transformation and proliferation but rather the expression of these nuclear antigens. ${ }^{23}$ We propose to study our tumours for these effector molecules as their expression would constitute strong evidence of a direct oncogenic role for the virus.

The unusual natural history and behaviour of primary brain lymphomas may be secondary to the presence of Epstein-Barr virus genome in the tumour cells. As Epstein-Barr virus infection and subsequent latency is universal, however, the presence of the virus in a lymphoma does not necessarily establish its role in tumourigenesis. Other studies using Southern blotting techniques have shown the presence of the Epstein-Barr virus genome in both Hodgkin's disease and large cell non-Hodgkin's lymphoma, including a small series of central nervous system lymphomas. ${ }^{41632}$ Our study, using the in situ technique, confirms an association between Epstein-Barr virus and primary brain lymphoma; its role as a potential progenitor or mere passenger needs further investigation.

We are grateful to $\mathrm{Mr}$ Stephen Toms for photographic assistance and Miss Jackie Stevenson for preparing the manuscript.

1 Hochberg FH, Miller DC. Primary central nervous system lymphoma. J Neurosurg 1988;68:835-53.

2 Russell DS, Rubinstein LJ, eds. Nervous system involvement by lymphomas, histiocytoses and leukaemias, In: Pathology of tumours of the nervous system. 5th $\mathrm{Ed}$. London: Edward Arnold, 1989:590-630.

3 Murphy JK, O'Brien CJ, Ironside JW. Morphologic and immunophenotypic characterisation of primary brain lymphomas using paraffin embedded tissue. Histopathology 1989;15:449-60.

4 Hochberg FH, Miller G, Schooley RT, Hirsch MS, Fearino $P$, Henle W. Central nervous system lymphoma related to Epstein-Barr virus. $N$ Engl J Med 1983;309:745-8.

5 Purtilo DT. Mononucleosis and other complications of Epstein-Barr virus infections. In: Sommers SS, Rosen PP, Eds. Pathology Annual Part 1. Connecticut: Appleton-
eds.
Century-Crofts, 1980:253-99.

6 Pattengale PK, Taylor CR, Panke T, et al. Selective immunodeficiency and malignant lymphoma of the central nervous system-possible relationship to EpsteinBarr virus. Acta Neuropathol (Berlin) 1979;48:165-9.

7 de-The G, Geser A, Day NE, et al. Epidemiological evidence for causal relationship between Epstein-Barr virus and Burkitt's lymphoma: results of the Ugandan virus and Burkitt's lymphoma: results of the Uature (Lond) 1978;274:756-61.

8 Lenoir GM. Role of the virus, chromosomal translocations and cellular oncogenes in the aetiology of Burkitt's lymphoma. In: Epstein MA, Achong BG, eds. The EpsteinBarr virus: recent advances. London: William Heinemann, 1986:184-205

9 Mirra SS, Check IJ, Porter JD, Cox GW, Miles NC, Weidenheim KM. Rapid evolution of central nervous lymphoma in renal transplant recipient. Lancet 1981; ii:868-9.

10 Cleary ML, Dorfman RF, Sklar J. Failure in immunological control of the virus infection: post transplant lymphomas. In: Epstein MA, Achong BG, eds. The Epstein-Barr virus: In: Epstein MA, Achong BG, eds. The Epstein-Barr virus:
recent advances. London: William Heinemann, 1986: recent advo $164-83$.

11 Hanto DW, Frizzera G, Purtilo DT, et al. Clinical spectrum of lymphoproliferative disorders in renal transplant recipients and evidence for the role of Epstein-Barr virus Cancer Res 1981;41:4253-61.

12 Frizzera G, Hanto DW, Gajl-Peczalska KJ, et al. Polymorphic diffuse B-cell hyperplasias and lymphomas in renal transplant recipients. Cancer Res 1981;41:4262-79.

13 Klein G. Specific chromosomal translocations and the genesis of B-cell-derived tumours in mice and men. Cell 1983;32:311-15.

14 Saemundsen AK, Berkel AI, Henle W, et al. Epstein-Barr virus carrying lymphoma in a patient with ataxia telangiectasia. Br Med J 1981;282:425-7.

15 Purtilo DT. Immune deficiency predisposing to EpsteinBarr virus-induced lymphoproliferative diseases: the $\mathrm{X}$ linked lymphoproliferative syndrome as a model. $A d v$ in Cancer Res 1981;34:279-312.

16 Rosenberg NL, Hochberg FH, Miller G, Kleinschmidt-De Masters BK. Primary central nervous system lymphoma related to Epstein-Barr virus in a patient with acquired immune deficiency syndrome. Ann Neurol 1986;20: 98-102.

17 Birx DL, Redfield RR, Tosato G. Defective regulation of Epstein-Barr virus infection in patients with acquired
immunodeficiency syndrome (AIDS) or AIDS-related immunodeficiency syndrome (AIDS) or
disorders. $N$ Engl J Med 1986;314:874-9.

18 Purtilo DT, Hutt L, Bhawan J, et al. Immunodeficiency to the Epstein-Barr virus in the $\mathrm{X}$-linked recessive lymphoproliferative syndrome. Clin Immunol Immunopathol 1978;9:147-56.

19 Mascucci MG, Sziget R, Ernberg I, et al. Cellular immune defects to Epstein-Barr virus-determined antigens in young males. Cancer Res 1981;41:4284-91.

20 Shope T, Dechairo D, Miller G. Malignant lymphoma in cotton-top marmosets following inoculation with Epsteincotton-top marmosets following inoculation with Epstein

21 Giovanella B, Nilsson K, Zech E, Yim O, Klein G, Stehliu JS. Growth of diploid, Epstein-Barr virus-carrying human lymphoblastoid cell lines heterotransplanted into nude mice under immunologically privileged conditions. In J Cancer 1979;24:103-13.

22 Lapin B, Agrba V, Voevodin A, Yakovleva L. The biology of lymphotrophic baboon herpes virus (HVP) and its association with malignant lymphoma. In: Yohn DS, Blakeslee R, eds. Advances in comparative leukaemia research 1981 . Proceedings of the Xth international symposium for comparative research on leukaemia and related posium for comparative research on leukaemia and

23 Dambaugh T, Hennessy K, Fennewald S, Kieff E. The virus genome and its expression in latent infection. In: Epstein MA, Achong BA, eds. The Epstein-Barr virus: recent advances. London: William Heinemann, 1986:14-45.

24 Wang F, Petti L, Braun D, Seung S, Kieff E. A bicistronic Epstein-Barr virus mRNA encodes two nuclear proteins in latently infected growth transformed lymphocytes. $J$ Virol 1987;61:945-54.

25 Lewis FA, Griffiths S, Dunnicliff R, Wells M, Dudding N, Bird CC. Sensitive in-situ hybridisation technique using biotin-streptavidin-polyalkaline phosphatase complex. $J$ Clin Pathol 1987;40:163-6.

26 Rickinson AB, Moss DJ, Wallace LE, et al. Long term Tcell-mediated immunity to Epstein-Barr virus. Cancer Res $1981 ; 41: 4216-21$

27 Rickinson $\mathrm{AB}$. Cellular immunological response to the virus infection. In: Epstein MA, Achong BG, eds. The EpsteinBarr virus: recent advances. London: William Heinemann, 1986:77-125.

28 Anonymous. DNA diagnosis and the polymerse chain reaction. [Editorial.] Lancet 1988;ii:1372-73.

29 Wang D, Leibowitz D, Wang F, et al. Epstein-Barr virus latent infection membrane $F$, et al. Epstein-Barr virus phocyte phenotype: deletion of the amino terminus abolphocyte phenotype: deletion of the amino

30 Wang F, Gregory CD, Rowe $M$, et al. Epstein-Barr virus nuclear protein 2 specifically induces expression of the $B$ nuclear protein 2 specifically induces expression of the B 1987;84:3452-6.

31 Young LS, Finnerty S, Brooks L, Scullion F, Rickinson AB, Morgan AJ. Epstein-Barr virus gene expression in malignant lymphomas induced by experimental virus infection of Cotton top Tamarins. J Virol 1989;63:1967-74

32 Staal SP, Ambinder R, Beschorner WE, Hayward GS, Mann R. A survey of Epstein-Barr virus DNA in lymphoid tissue; frequent detection in Hodgkin's disease. Am J Clin Pathol 1989;91:1-5. 